\title{
Studies of Human Megakaryocytopoiesis Using an Anti-Megakaryocyte Colony-stimulating Factor Antiserum
}

\author{
Hain H. Yang, Edward Bruno, and Ronald Hoffman \\ Hematology/Oncology Section, Department of Medicine, Indiana Elks Cancer Research Center, \\ Indiana University School of Medicine, Indianapolis, Indiana 46223
}

\begin{abstract}
We produced an antiserum by immunizing rabbits with purified human megakaryocyte colony stimulating factor (Meg-CSF). With the use of an anti-Meg-CSF IgG fraction ( $\left.A_{M}-I g G\right)$, we detected immunoreactive Meg-CSF both in human aplastic anemia serum (AAS) and normal serum. Based on our immunological and biological analyses, Meg-CSF appeared to be antigenically as well as functionally distinct from human urinary erythropoietin (EPO) and thrombopoietic stimulating factor. The $A_{M}$-IgG fraction was able to suppress the ability of both aplastic anemia serum and purified Meg-CSF to promote megakaryocyte colony formation. In addition, the supernatant formed after immune precipitation of the AAS with $\mathbf{A}_{\mathbf{M}}$-IgG no longer possessed MegCSF-like activity. The $A_{M}$-IgG did not suppress the ability of EPO, phytohemagglutinin-stimulated leukocyte conditioned medium (PHA-LCM), or PHA-LCM + EPO to promote erythroid, granulocyte-macrophage, or mixed colony formation, respectively. The use of this antibody has further defined the dependency of human megakaryocytopoiesis on Meg-CSF.
\end{abstract}

\section{Introduction}

The regulation of human megakaryocytopoiesis and thrombopoiesis is only partially understood. Recently, hematopoietic growth factors able to specifically stimulate megakaryocytopoiesis have been reported to be present in the plasma, serum, and urine of patients with hypomegakaryocytic thrombocytopenia (1-4). It has been suggested that at least two humoral factors, megakaryocyte colony stimulating factor (Meg-CSF) ${ }^{1}$ and thrombopoietin (TPO), which exert their effect on different cellular targets, are important in the regulation of in vitro megakaryocytopoiesis (5).

Address reprint requests to Dr. Yang, Department of Medicine, Indiana University School of Medicine, Clinical Building, Room 379, 541 Clinical Drive, Indianapolis, IN 46223.

Received for publication 6 August 1985 and in revised form 25 February 1986.

1. Abbreviations used in this paper: AAS, aplastic anemia serum; $\mathrm{A}_{\mathbf{M}}$ IgG, anti-megakaryocyte colony stimulating factor IgG fraction; BFU$\mathrm{E}$, burst forming unit-erythroid; CFU-E, colony forming unit-erythroid; CFU-GEMM, colony forming unit-granulocyte-erythroid-macrophagemegakaryocyte; CFU-GM, colony forming unit-granulocyte-macrophage; CFU-M, colony-forming unit-megakaryocyte; EPO, erythropoietin; IL3, interleukin 3; Meg-CSF, megakaryocyte colony stimulating factor; PAGE, polyacrylamide gel electrophoresis; PHA-LCM, phytohemagglutinin-stimulated leukocytic conditioned medium; TSF, thrombopoietic stimulating factor.

J. Clin. Invest.

(c) The American Society for Clinical Investigation, Inc.

0021-9738/86/06/1873/08 \$1.00

Volume 77, June 1986, 1873-1880
Meg-CSF appears to be distinct from TPO, a substance present in thrombocytopenic plasma, which is responsible for megakaryocyte polyploidization. The effect of TPO is quantitated by its ability to stimulate the incorporation of radioisotopes into newly synthesized platelets in recipient animals (6). Meg-CSF influences megakaryocytopoiesis by stimulating the differentiation and proliferation of the colony forming unit-megakaryocyte (CFU-M) (4, 7). Thrombopoietic stimulatory factor (TSF) purified from human embryonic kidney cell conditioned medium, by contrast, does not alter CFU-M cloning efficiency, $(7,8)$ but accelerates the development of small immature megakaryocytes into single, large, easily recognizable megakaryocytes. Vainchenker et al. (9) have reported that erythropoietin (EPO) promotes the formation of human megakaryocyte colonies, which suggests that EPO may also play a role in the regulation of megakaryocytopoiesis. This observation is of interest since it may provide experimental support for the clinical observation that active megakaryocytopoiesis and thrombopoiesis often accompany active erythropoiesis.

We have recently purified human Meg-CSF into homogeneity. Meg-CSF increases megakaryocyte colony formation in culture but is incapable of supporting erythroid or granulocytemacrophage colony formation. The available evidence suggests that the active molecule plays an important role in the regulation of human megakaryocytopoiesis. To further define the relationship between purified Meg-CSF, EPO, and TSF, we have succeeded in preparing a polyclonal IgG fraction against the purified human Meg-CSF. We report here an immunological analysis of a number of potential sources of Meg-CSF-like activity. In addition, we show that the anti-Meg-CSF IgG fraction $\left(\mathrm{A}_{\mathrm{M}-\mathrm{IgG})}\right.$ reduces the ability of aplastic anemia serum (AAS) and purified Meg-CSF to enhance CFU-M cloning efficiency, confirming the pivotal role that this factor plays in the regulation of the early events occurring during human megakaryocytopoiesis.

\section{Methods}

Human subjects. Bone marrow aspirations were obtained from the posterior iliac crests of hematologically normal individuals. Human AB serum was obtained from normal volunteers while AAS was obtained from patients with severe bone marrow aplasia. Sera were stored at $-20^{\circ} \mathrm{C}$ in aliquots before use. The bone marrow and serum specimens were gathered after informed consent was obtained according to the guidelines of the Indiana University Committee for Protection of Human Subjects.

Source of Meg-CSF. Meg-CSF was purified according to the method of Hoffman and co-workers (7). In addition, the biologically active fraction obtained from affinity chromatography was further loaded onto a preparative sodium dodecyl sulfate (SDS)-polyacrylamide gel for electrophoresis to recover the 46,000 -mol-wt protein and to assure its homogeneity.

Recovery of biologically active factor from SDS-polyacrylamide gel electrophoresis (PAGE) gel. Samples $(2 \mathrm{ml})$ of concentrated fractions obtained after wheat germ lectin sepharose CL-6B chromatography were 
run on slab gels $(1.5 \times 140 \times 110 \mathrm{~mm})$ with standard molecular weight markers. At the end of the run, the distance from the tracking dye to the top of the running gel was carefully measured. A strip of the gel was cut vertically for staining as a template and the other part was retained for measurement of biological activity. The unstained part of the gel was sliced horizontally in sections according to the position of bands on the stained gel. The gel slices were shaken overnight at $4^{\circ} \mathrm{C}$ in $10 \mathrm{ml}$ of 0.02 $\mathrm{M}$ sodium phosphate buffer, $\mathrm{pH}$ 7.2. The buffer solution was decanted and saved. This extraction step was repeated once and the gel slices were removed and discarded. These supernatants were combined and centrifuged to further remove gel particles and were dialyzed against double distilled water for $24 \mathrm{~h}$ with three changes of water, followed by ultrafiltration using an Amicon cell model 52 concentrator (Amicon Corp., Danvers, MA). They were then lyophilized and stored at $-20^{\circ} \mathrm{C}$ until reconstitution in alpha-media for use in the biological assay or for use as an immunogen. When comparing the unstained portion of the gel with the biologically assayed portion, we took gel swelling into account.

Protein estimations. Protein concentration was estimated by the method of Lowry et al. (10) using bovine serum albumin (BSA) as a standard. The absorbance at $280 \mathrm{~nm}$ was used to monitor the relative protein concentrations of column effluents.

Immunization schedule and antibody isolation. New Zealand white rabbits were immunized by subcutaneous injection of $400 \mu \mathrm{g}$ of purified Meg-CSF emulsified in $3 \mathrm{ml}$ of Freund's complete adjuvant (Gibco, Grand Island, NY) 4 wk later and after a subsequent 2-wk period, an additional $150 \mu \mathrm{g}$ of the protein in incomplete Freund's adjuvant was administered. The rabbits were bled 6-14 $\mathrm{d}$ after the last booster injections. The antibody-containing serum was heat-inactivated at $56^{\circ} \mathrm{C}$ for $30 \mathrm{~min}$. The anti-Meg-CSF immunoglobulin fraction was prepared by precipitation with $45 \%$ ammonium sulfate followed by subsequent dialysis of the precipitate against phosphate-buffered saline (PBS) ( $\mathrm{pH} 7.4$ ), and purification on a DEAE affi-gel Blue Column (Bio-Rad Laboratories, Richmond, CA). This IgG fraction was designated as $A_{M^{-}}-\mathrm{IgG}$, and was stored in $0.01 \mathrm{M}$ potassium phosphate-buffered saline $\left(\mathrm{pH} \mathrm{7.4)}\right.$ at $-80^{\circ} \mathrm{C}$ before use. The protein concentration was adjusted to $2.7 \mathrm{mg} / \mathrm{ml}$.

Electrophoresis. $10 \%$ polyacrylamide gels were run according to the method of Laemmli (11). Before application onto slab $(1.5 \times 110 \times 140$ $\mathrm{mm}$ ) gels containing $0.1 \%$ SDS, the samples were heated to $100^{\circ} \mathrm{C}$ for $3 \mathrm{~min}$ in the sample buffer. Duplicate gels were fixed and stained with Coomassie Brilliant Blue R-250 in acetic acid/methanol/water (1:5:4 by volume) or with the highly sensitive silver stain (Bio-Rad Laboratories). Known molecular weight proteins (Bio-Rad Laboratories) were simultaneously run on the gels to serve as molecular weight reference markers. Markers consisted of $5 \mu \mathrm{g}$ of myosin-H chain $(200,000 \mathrm{~mol} \mathrm{wt})$, betagalactosidase (130,000 mol wt), phosphorylase B (92,000 mol wt), BSA $(68,000 \mathrm{~mol} \mathrm{wt})$, ovalbumin $(45,000 \mathrm{~mol} \mathrm{wt})$, carbonic anhydrase $(32,000$ mol wt), and soybean trypsin inhibitor $(20,000 \mathrm{~mol} \mathrm{wt})$. Preparative slab gel experiments $(3 \times 110 \times 140 \mathrm{~mm})$ were performed in the same manner as analytical gels except the sample remained in its nonreduced form. Two-dimensional electrophoresis was carried out according to the method of O'Farrell (12).

Immunoelectrophoresis was carried out as described by Grabar and Williams (13). Double-immunodiffusion experiments were performed by applying the technique of Ouchterlony (14) using immunoelectrofilms and double-diffusion plates (Kallestad Laboratories, Inc., Austin, TX).

Iodination of human Meg-CSF. A modification of the procedure described by Stanley (15) and Stagg (16) was used to iodinate Meg-CSF. In brief, purified Meg-CSF $(1 \mu \mathrm{g})$ was resuspended in $40 \mu \mathrm{l}$ of $0.1 \mathrm{M}$ sodium phosphate, $\mathrm{pH} 7.6$, containing $10 \%$ dimethyl sulfoxide and 100 $\mu \mathrm{g} / \mathrm{ml}$ of polythylene glycol $6000.10 \mu \mathrm{l}$ of ${ }^{125} \mathrm{I}-\mathrm{Na}$ containing $1 \mathrm{mCi}$ were added, followed by $20 \mu \mathrm{l}$ of a solution of chloramine-T $(1 \mathrm{mg} / \mathrm{ml})$. The mixture was incubated at $4^{\circ} \mathrm{C}$ for $5 \mathrm{~min}$, and $20 \mu \mathrm{l}$ of both sodium metabisulfite $(3 \mathrm{mg} / \mathrm{ml})$ and $\mathrm{KI}(0.1 \mathrm{M})$ were added; then $500 \mu \mathrm{l}$ of BSA $(10 \mathrm{mg} / \mathrm{ml})$ was added. Iodinated Meg-CSF was separated from unbound ${ }^{125} \mathrm{I}$ by chromatography on 10-ml disposable columns of sephadex G-50 run in $0.01 \mathrm{M}$ sodium phosphate buffer, $\mathrm{pH} 7.6$, containing $0.1 \mathrm{M} \mathrm{NaCl}$.

Immune precipitation of radiolabeled Meg-CSF and Meg-CSF present in human serum. The purified $A_{M}$-IgG fraction or a control normal rabbit
IgG fraction was diluted in PBS to which either radiolabeled Meg-CSF, human $\mathrm{AB}$ serum, or AAS was added in a final volume $0.2 \mathrm{ml}$. These mixtures were incubated for $2 \mathrm{~h}$ at $37^{\circ} \mathrm{C}$ and then overnight at $4^{\circ} \mathrm{C} .10$ $\mathrm{mg}$ of protein A Sepharose swollen in PBS was added and the immune complexes were precipitated. This mixture was allowed to stand at $23^{\circ} \mathrm{C}$ for $2 \mathrm{~h}$ and was subsequently centrifuged at $8,000 \mathrm{~g}$ for $5 \mathrm{~min}$ in a microfuge (Model 59-A; Fisher Scientific Co., Pittsburgh, PA). The precipitates were washed three times with PBS and the complexes were eluted off with $10 \%$ SDS and $10 \%$ beta-mercaptoethanol at $100^{\circ} \mathrm{C}$ for 5 $\mathrm{min}$. The complexes were analyzed for radioactivity by using a gamma counter (Model 5500; Beckman Instruments, Inc., Fullerton, CA) and were analyzed by SDS-PAGE by the method of Laemmli (11). After the completion of electrophoresis, the radiolabeled Meg-CSF SDS-PAGE gel was dried and autoradiographed. The polypeptides obtained from the serum specimens were transferred electrophoretically to nitrocellulose paper for Western blotting. The high-affinity binding of ${ }^{125} \mathrm{I}-\mathrm{Meg}-\mathrm{CSF}$ to $A_{M}-I g G$ precipitated by protein $A$ was determined by subtraction of low-affinity binding obtained by the addition of 300 -fold excess unlabeled Meg-CSF.

Western blotting. Western blotting was performed according to the method of Towbin et al. (17) using a Trans-Blot cell (Bio-Rad Laboratories). Polypeptide transfer to nitrocellulose paper $(15 \times 15 \mathrm{~cm})$ was accomplished immediately after the termination of electrophoresis and incubated with $A_{M}-\mathrm{IgG}$ for $2 \mathrm{~h}$, then reacted with ${ }^{125} \mathrm{I}$-protein $\mathrm{A}\left(10^{5}-\right.$ $10^{6} \mathrm{cpm}$; Amersham Corp., Arlington Heights, IL; specific activity, 30 $\mu \mathrm{Ci} / \mathrm{mg}$; concentration, $100 \mu \mathrm{Ci} / \mathrm{ml})$. Bound ${ }^{125} \mathrm{I}$ was detected by autoradiography using X-Omat AR film (Eastman Kodak Co., Rochester, NY) and Dupont Lightening (E. I. Du Pont de Nemours \& Co., Inc., Wilmington, DE) plus intensifying screens at $-70^{\circ} \mathrm{C}$ for $24-48 \mathrm{~h}$.

Megakaryocyte colony stimulating factor assay. Meg-CSF was assayed in plasma clot cultures containing $5 \times 10^{5}$ bone marrow mononuclear cells (18). The bone marrow aspirate was diluted 1:1 with alpha-medium minus nucleosides (Gibco, Grand Island, NY), containing preservativefree sodium heparin at $20 \mathrm{U} / \mathrm{ml}$ and layered over an equal volume of Ficoll-Paque (specific gravity, $1.077 \mathrm{~g} / \mathrm{cm}^{3}$; Pharmacia Fine Chemicals, Piscataway, NJ). Density centrifugation was performed at $500 \mathrm{~g}$ for 25 min at $4^{\circ} \mathrm{C}$ in a Beckman model TJ-6R centrifuge (Beckman Instruments, Inc.). The interface mononuclear cell layer was collected and washed with alpha-medium minus nucleosides containing $2 \%$ fetal calf serum. Mononuclear cells at $5 \times 10^{5}$ cells/ml were cultured in $1-\mathrm{ml}$ volumes in 35-mm petri dishes. The plasma clot technique of McLeod et al. (18) was modified by the substitution of heat-inactivated human AB serum for fetal calf serum, and alpha-medium minus nucleosides for NCTC109 medium and Eagle's minimal essential medium with Hank's balanced salt solution. Samples to be assayed for Meg-CSF activity were diluted in alpha-medium minus nucleosides at several dilutions. The final 1-ml aliquot of each culture contained the following supplements: alpha-media minus nucleosides, sodium bicarbonate (1.2\%), nonessential amino acids $(0.01 \mathrm{mmol} / \mathrm{ml}), \mathrm{L}$-glutamine $(0.4 \mathrm{mmol} / \mathrm{ml})$, and sodium pyruvate $(0.2$ $\mathrm{mmol} / \mathrm{ml}$ ). Culture dishes were incubated for 10-12 d (unless otherwise stated) at $37^{\circ} \mathrm{C}$ in a $100 \%$ humidified atmosphere of $5 \% \mathrm{CO}_{2}$ in air. Harvesting was performed by in situ fixation with methanol/acetone (1: 3) for $20 \mathrm{~min}$, washing with $0.01 \mathrm{M} \mathrm{PBS,} \mathrm{pH} \mathrm{7.2,} \mathrm{then} \mathrm{distilled} \mathrm{water,}$ and subsequently air dried. Plasma clots were stored frozen at $-20^{\circ} \mathrm{C}$ until immunofluorescent staining was performed.

Immunofluorescent identification of human megakaryocyte colonies. Whole rabbit anti-PGP antiserum, previously established as a megakaryocyte specific marker (8), was diluted in PBS (1:200), layered over the fixed plasma clot culture, and incubated for $60 \mathrm{~min}$ at room temperature in $100 \%$ humidified air. After washing three times with PBS, the specimens were reincubated for an additional $60 \mathrm{~min}$ with fluorescein-conjugated goat anti-rabbit IgG (Meloy Laboratories, Inc., Springfield, VA) diluted in PBS, final concentration, $0.36 \mathrm{mg}$ protein/ml. After being washed with PBS, the specimens were counterstained with $0.125 \%$ Evan's Blue for $5 \mathrm{~min}$, washed with distilled water, and mounted in isotonic barbital buffer, $\mathrm{pH} 8.6$, in glycerol (1:3).

Plasma clot cultures were scored in situ in order to enumerate fluorescein positive colonies. The $35-\mathrm{mm}$ petri dishes were inverted and 
the base area was completely scanned with a fluorescence microscope at $100 \times$ (Zeiss standard microscope 18 with IV FL vertical fluorescent illuminator; Carl Zeiss, Inc., Thornwood, NY). A megakaryocyte colony was defined as a cluster of three or more intensely fluorescent cells. Each study was performed in duplicate to quadruplicate. Specific activity of Meg-CSF preparations was calculated from the number of megakaryocyte colonies per milligram protein from the linear portion of the dose response curve.

Assay for other hematopoietic colonies. Both BFU-E and CFU-E derived colony assays were performed in plasma clot cultures as previously described (19). Human EPO, specific activity, 30-50 U/mg of protein (Toyobo Co., LTD, Osaka, 530 Japan) was used in these studies. Plasma clots were fixed in situ with $5 \%$ glutaraldehyde in $0.01 \mathrm{M}$ phosphate buffer (pH, 7.0-7.2). Colony forming unit-erythroid (CFU-E) and burst forming unit-erythroid (BFU-E) derived colonies were harvested after 7 and 12-14 d of incubation, respectively. Cultures were stained with $1 \%$ benzidine and hematoxylin as previously described (19). Maximum growth of CFU-E and BFU-E derived colonies in this modified plasma clot assay system was seen at EPO concentrations of 0.5 and $1.0 \mathrm{IU} / \mathrm{ml}$, respectively.

The colony assay for granulocyte-macrophage colony-forming units (CFU-GM) was carried out according to the method of Fauser and Messner (20). In brief, marrow mononuclear cells were suspended in $35 \mathrm{~mm}$ Lux standard tissue culture dishes, containing a 1-ml mixture of Iscove's modified Dulbecco's medium (IMDM; Gibco Laboratories), $0.8 \%$ methylcellulose, $30 \%$ fetal bovine serum, $10 \%$ medium conditioned by leukocytes from patients with hemochromatosis in the presence of $1 \%$ phytohemagglutinin-stimulated leukocyte conditioned medium (PHA-LCM), and $5 \times 10^{-5} \mathrm{M}$ 2-mercaptoethanol. Dishes were incubated at $37^{\circ} \mathrm{C}$ in a humidified atmosphere flushed with $5 \% \mathrm{CO}_{2}$ in air. Colonies were scored with an inverted microscope after 13-14 d of incubation. Clusters of $\geq 40$ cells, many of which had typical band or segmented polymorphonuclear leukocyte morphology, were defined as CFU-GM derived colonies. The assay for human granulocyte-erythroid-macrophagemegakaryocyte (CFU-GEMM) derived colonies as described by Fauser and Messner (21) was used to assess the effect of growth factors on multipotential colony forming unit cells.

Neutralization test. The ability of the anti-Meg-CSF IgG fraction $\left(A_{M}-\mathrm{IgG}, 2.7 \mathrm{mg} / \mathrm{ml}\right)$ to neutralize $\mathrm{Meg}-\mathrm{CSF}$ activity was assessed using two methods. First, the anti-Meg-CSF IgG fraction ( $A_{M}-I g G, 2.7 \mathrm{mg} /$ $\mathrm{ml})$ or the $\mathrm{IgG}$ fraction $(2.7 \mathrm{mg} / \mathrm{ml})$ of normal rabbit serum was diluted in saline and mixed with an equal volume of either AAS, purified MegCSF, PHA-LCM, or a partially purified preparation of human urinary erythropoietin and incubated at $25^{\circ} \mathrm{C}$ for $1 \mathrm{~h}$ before adding to the cultures. Control cultures were established with the same stimulus mixed with an equal volume of physiological saline. The ability of these mixtures to promote megakaryocyte, granulocyte-macrophage, or erythroid-derived colony formation by normal human marrow cells was determined using the various assays described above. The number of each type of hematopoietic colony was determined. The second method for assessing the neutralizing ability of the $A_{M}-\operatorname{IgG}$ was as follows: $A_{M}-\operatorname{IgG}$ and normal rabbit IgG were diluted in saline as above and mixed with an equal volume of AAS and incubated at $25^{\circ} \mathrm{C}$ for $1 \mathrm{~h}$, followed by an additional incubation at $4^{\circ} \mathrm{C}$ overnight. The immune complexes that were formed were precipitated by adding $10 \mathrm{mg}$ of protein A-Sepharose swollen in PBS. This mixture was allowed to rotate at $4^{\circ} \mathrm{C}$ for $2 \mathrm{~h}$ and was subsequently centrifuged at $8,000 \mathrm{~g}$ for $5 \mathrm{~min}$ in a Fisher microfuge (Model 59-A). The ability of the supernatants to promote CFU-M derived colony formation by normal marrow cells was determined. In order to further define the specificity of the $A_{M}-\operatorname{IgG}$ neutralizing activity, we assessed the ability of increasing amounts of purified Meg-CSF to overwhelm the antibody effect. The inhibitory activity of the normal rabbit IgG or the $A_{M}$-IgG was expressed as the percent of the control number of colonies formed. The titer was expressed as that dilution which caused a $50 \%$ reduction in colony numbers.

Statistics. The student $t$ test was performed with a statistical package compatible with an Apple II computer (Apple Computer, Cupertino, CA).

\section{Results}

The immunogen used to produce the anti-Meg-CSF antibody was purified from the plasma of a patient with hypomegakaryocytic thrombocytopenia according to the methods of Hoffman and co-workers (7). The active Meg-CSF band was cut out and extracted from the preparative SDS-polyacrylamide gel, thus recovering $60-80 \%$ of the loaded sample. When $10 \mu \mathrm{g}$ of the extracted protein was analyzed with two-dimensional gel electrophoresis, it migrated as a single band and showed no evidence of contamination with other proteins (Fig. 1).

Both rabbits immunized with purified Meg-CSF produced antisera to Meg-CSF. IgG fractions were purified from preimmune rabbit serum and antiserum obtained from the immunized rabbits. The preparations revealed a single band in the gamma globulin region when purified IgG fractions were examined in SDS-polyacrylamide gel at $\mathrm{pH}$ 8.8. The reactivity of $\mathrm{A}_{\mathrm{M}}$-IgG with Meg-CSF was examined by means of immunodiffusion, immunoelectrophoresis, and Western blotting.

As shown in Fig. $2 \mathrm{~A}$, the purified Meg-CSF formed a single precipitin line with the antibody when placed in an immunodiffusion system. As shown in Fig. $2 B$, the antibody did not form a precipitin line with TSF, purified from human embryonic kidney cell conditioned media (gift of T. P. McDonald, University of Tennessee, Knoxville, TN), or human urinary EPO (specific activity, $500 \mathrm{U} / \mathrm{mg}$ of protein, Alpha-Therapeutics Corp., Los Angeles, CA). However, the antibody did form a single precipitin line with Meg-CSF purified by preparative electrophoresis (Fig. $2 \mathrm{~B}$ ) and the fraction obtained after high performance liquid chromatography (Fig. 3), which suggests that the Meg-CSF was immunochemically distinct from both TSF and EPO. The preimmune IgG fraction was run under the same conditions as the immune IgG fraction and at various concen-

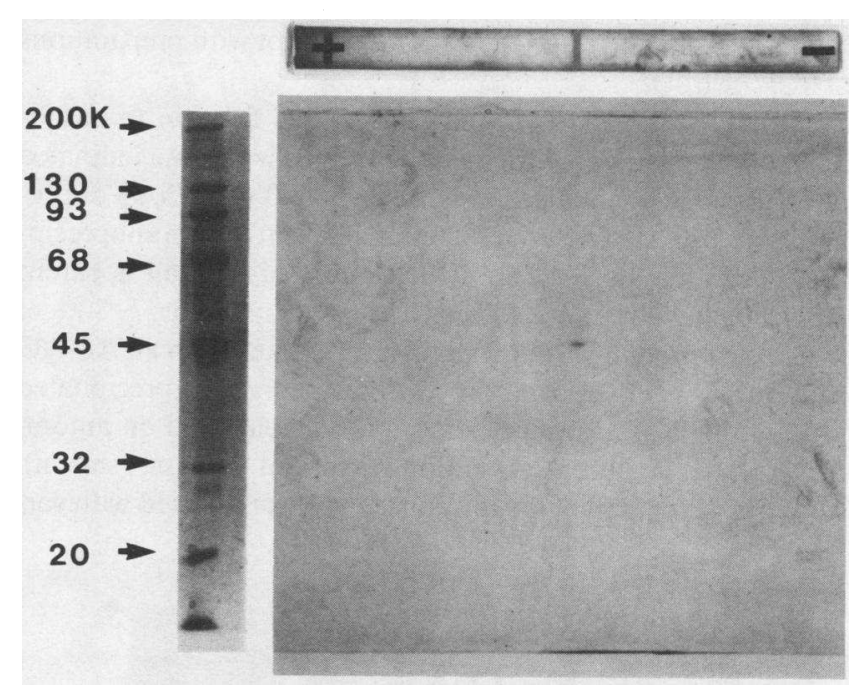

Figure 1. Two-dimensional SDS-PAGE of purified human megakaryocytic stimulating factor. The first dimension was isoelectric focusing in a pH 3.5-10 gradient, 5\% acrylamide gel containing $8 \mathrm{M}$ urea and $1 \%$ ampholytes. A silver stained gel $(5 \times 115 \mathrm{~mm})$ is shown horizontally at the top of the electrophoregram. The second dimensional gel of $10 \%$ acrylamide, $1.5-\mathrm{mm}$-thick, was run by loading an isoelectric focusing gel $(1 \times 115 \mathrm{~mm})$ on the top of the slab SDS-gel. The gel was stained using the Bio-Rad Silver Stain (Bio-Rad Laboratories). At left, known molecular weight proteins are demonstrated. 


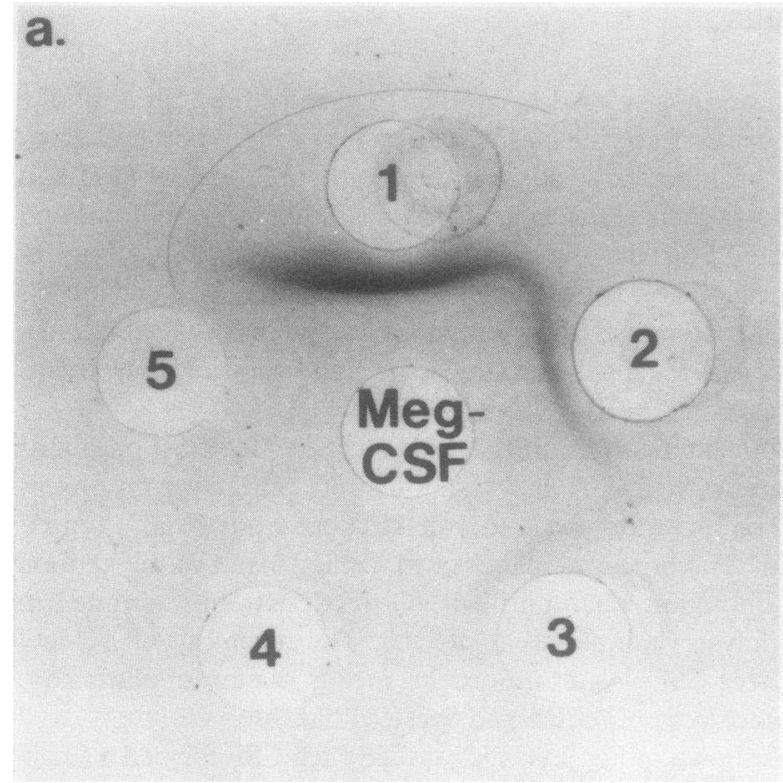

Figure 2. Analysis of various hematopoietic growth factors using immunodiffusion with the anti-Meg-CSF IgG fraction. The experiments were carried out in $1 \%$ agarose solution in $0.05 \mathrm{M}$ Tris- $\mathrm{HCl}$ buffer, $\mathrm{pH}$ 7.5 , containing $0.15 \mathrm{M} \mathrm{NaCl}$ and $0.02 \% \mathrm{NaN}_{3}$. (a) Center well contains $10 \mu$ l of human purified Meg-CSF in a concentration of $0.1 \mathrm{mg} /$ $\mathrm{ml}$ and wells 1-5 contain $5 \mu$ lof twofold serial dilutions of rabbit $A_{M^{-}}$ IgG $(2.7 \mathrm{mg} / \mathrm{ml})$ starting with undiluted $A_{M^{-}}-\mathrm{IgG}$ in well 1 . (b) Rabbit

trations of purified Meg-CSF. No precipitin lines formed with the preimmune IgG fraction (data not shown).

Using immunoprecipitation and Western blotting techniques (Fig. 4), several potential sources of hematopoietic growth factors were also examined for reactivity with the anti Meg-CSF IgG fraction. The $A_{M}-\operatorname{IgG}$ formed a precipitin band with AAS, normal human serum, and purified Meg-CSF but not with preparations of TSF or EPO.

In Fig. 5, the ability of purified $A_{M}-\mathrm{IgG}$ fraction to immunoprecipitate iodinated Meg-CSF was examined. The iodinated purified Meg-CSF had a specific activity of $0.45 \mathrm{mCi} / \mu \mathrm{g}$ of protein. The anti-Meg-CSF IgG fraction efficiently immunoprecipitated the iodinated protein which migrated with an apparent molecular weight of 46,000 on SDS-PAGE analysis. $\sim 80 \%$ of the labeled protein was maximally precipitated with an $\mathrm{A}_{\mathrm{M}}-\mathrm{IgG}$ concentration of $0.67 \mathrm{mg} / \mathrm{ml}$. Normal rabbit IgG precipitated $<1 \%$ of the labeled protein and no detectable band on autoradiography at a concentration up to $2 \mathrm{mg} / \mathrm{ml}$ (data not shown). The autoradiograph of the immune complexes formed with var-

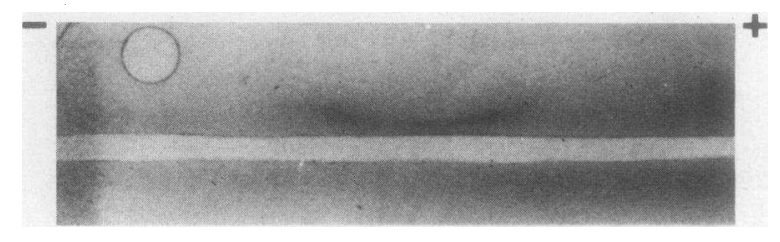

Figure 3. Immunoelectrophoretogram of purified Meg-CSF. Meg-CSF was obtained from the major peak following purification by reversephase high pressure liquid chromatography. Trough, $\mathbf{A}_{\mathbf{M}}-\mathrm{IgG}$; antigen well, human Meg-CSF. A single precipitin line was revealed.

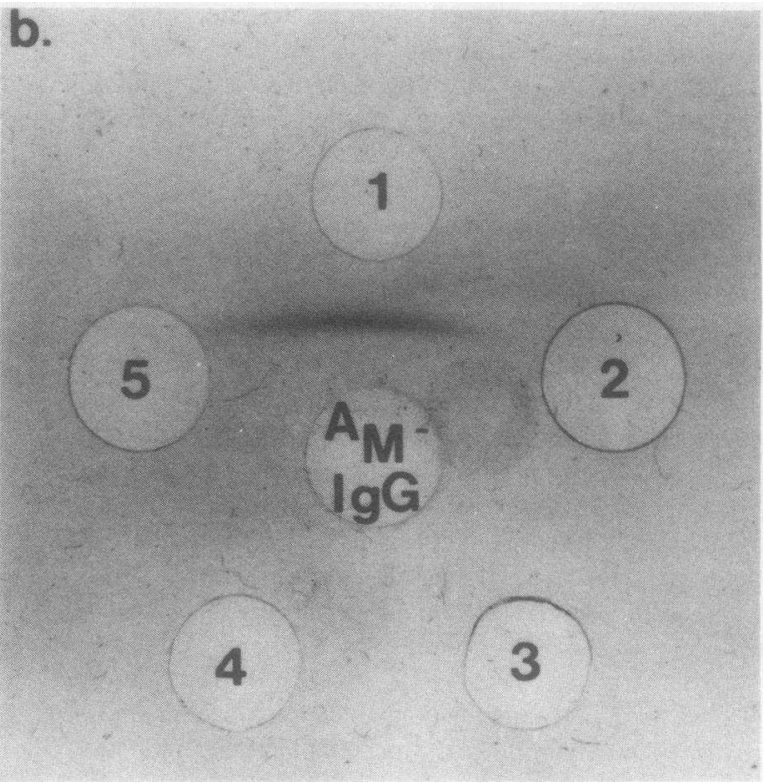

$A_{M}-\operatorname{lgG}(5 \mu l$ of $2.7 \mathrm{mg} / \mathrm{ml})$ was placed in center well. Growth factors of comparable concentrations were placed in the outer wells as follows: 1, purified human Meg-CSF (1.0 $\mu \mathrm{g}) ; 2$, preimmune rabbit IgG $(5.0 \mu \mathrm{g}) ; 3$, TSF (purified from human embryonic kidney cell-conditioned media, $1.0 \mu \mathrm{g}$ ); 4, and 5, human urinary erythropoietin (sp act, $500 \mathrm{U} / \mathrm{mg}$ of protein, Lot No. EH009TO, 1.0 and $2.0 \mu \mathrm{g}$ per well, respectively).

ious dilutions of $\mathrm{A}_{\mathbf{M}}$-IgG and iodinated Meg-CSF is shown in Fig. 6.

Neutralization of Meg-CSF activity present in AAS and purified human Meg-CSF by the $A_{M}-\operatorname{IgG}$ fraction is demonstrated in Table $I$. The $A_{M}-\operatorname{IgG}$ at various concentrations was unable to alter the baseline megakaryocyte colony formation that occurs in the absence of added Meg-CSF (data not shown). The $\mathrm{A}_{\mathrm{M}^{-}}$ IgG was able to neutralize the megakaryocyte colony stimulating activity present in AAS or purified Meg-CSF at a statistically significant level $(P<0.001)$. At a dilution of $1: 256$, the $A_{M}$-IgG resulted in a 55\% reduction in megakaryocyte colony formation stimulated by AAS. As shown in Table II, this neutralization effect was overcome by adding increasing amounts of purified Meg-CSF. When the supernatants of AAS from which the MegCSF had been immune-precipitated were incubated with protein A Sepharose beads to remove free residual $A_{M}-\operatorname{IgG}$ Meg-CSF immune qomplexes, these fractions still were unable to promote megakaryocyte colony formation. Neutralization of the ability of purified Meg-CSF to promote megakaryocyte colony formation occurred up to a 1:1,024 dilution of $A_{M}-\mathrm{IgG}$.

The inability of the anti Meg-CSF IgG fraction to neutralize the effect of EPO in promoting CFU-E and BFU-E derived colony formation is shown in Table III. In addition, treatment with $\mathrm{A}_{\mathbf{M}}$-IgG did not influence CFU-GEMM or BFU-E derived colony formation when stimulated by EPO + PHA-LCM. Similar treatments did not influence the ability of PHA-LCM to promote CFU-GM derived colony formation. This lack of effect on in vitro erythropoiesis, granulopoiesis, and on the formation of mixed colonies suggests that $A_{M}$-IgG does not act by a direct toxic action on the colony-forming cells or by reacting with nutrients in the culture medium. Therefore, these experiments 


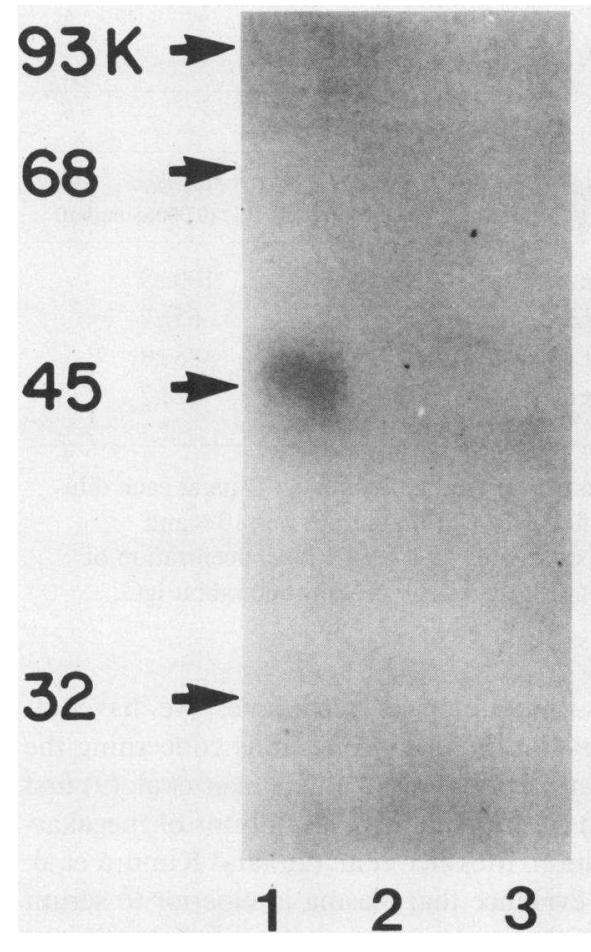

substantiate the specificity of the $A_{M}$-IgG. In this series of experiments and in previously reported studies $(4,8)$ we have been unable to demonstrate an effect of PHA-LCM or EPO on CFU$M$ derived colony formation. The effect of $A_{M}-I g G$ on EPO and PHA-LCM stimulated megakaryocyte colony formation was therefore not assessed.

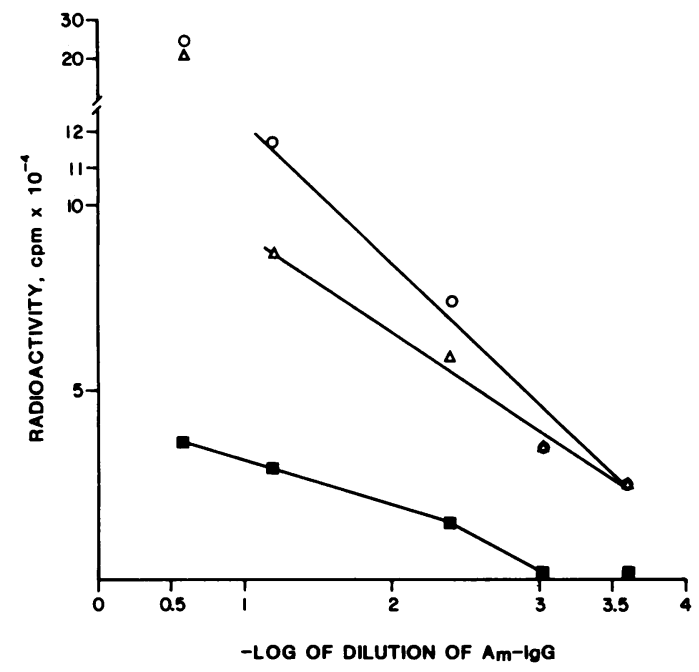

Figure 5. Immune precipitation binding curve of ${ }^{125} \mathrm{I}-\mathrm{Meg}-\mathrm{CSF}$ to $\mathrm{A}_{\mathbf{M}}$ IgG. $\sim 240,000 \mathrm{cpm}$ of ${ }^{125} \mathrm{I}-\mathrm{Meg}-\mathrm{CSF}(0.4 \mathrm{ng})$ and $0.1 \mathrm{ml}$ of fourfold serial dilutions of $A_{M}-I g G$ were used for each point. The total binding radioactivity $(O)$ was determined from the precipitated immune-complexes that were dissociated and eluted off from protein A Sepharose. Low-affinity binding radioactivity was obtained by adding 300 -fold excess of unlabeled Meg-CSF to labeled Meg-CSF ( $\square$ ). Specific, high-affinity binding radioactivity $(\Delta)$ was calculated by taking the difference between the total and low-affinity binding.
Figure 4. Western blotting of immunoprecipitates of various hematopoietic growth factors and human sera with

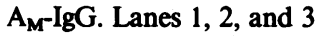
represent purified Meg-CSF $(2.0 \mu \mathrm{g})$, human urinary EPO $(7.0 \mu \mathrm{g})$, and thrombopoietic stimulating factor $(3.0 \mu \mathrm{g})$, respectively. Lanes 4, 5, and 6 represent complexes obtained from purified Meg-CSF (5.0 $\mu \mathrm{g})$, normal AB serum (10\%), and AAS (10\%) subjected to 10\% SDS-PAGE, respectively. Polypeptides were transferred to nitrocellulose paper and the immune-complexes bound to ${ }^{125}$ I-protein A were detected by autoradiography. Molecular weight markers were indicated by arrows (example: $93 \mathrm{~K}=93,000 \mathrm{~mol}$ wt).

\section{Discussion}

Factors that control human thrombopoiesis and megakaryocytopoiesis have not been well characterized. Recently, clonal culture techniques have been developed that allow the quantitation of human megakaryocyte colony forming units (CFU-M) in bone marrow and peripheral blood $(8,22)$. A number of investigators have detected factors from a variety of sources that promote megakaryocyte colony formation (23-29). Crude human EPO, sheep EPO $(18,28)$, homogeneously purified human urinary EPO (27), and TSF (29), have also been shown to enhance

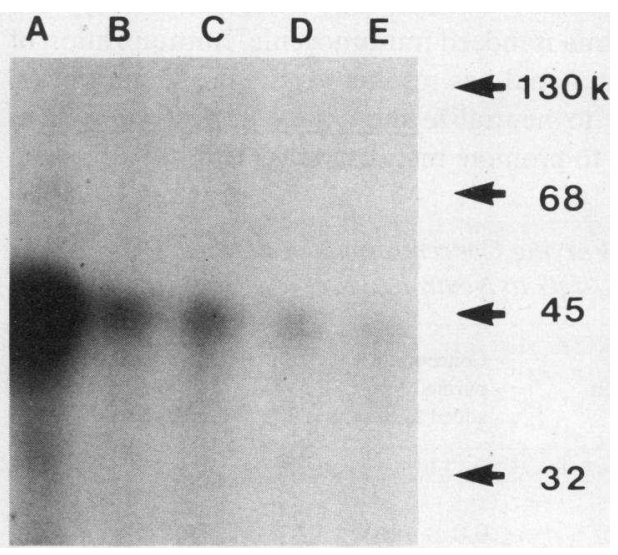

Figure 6. Immune precipitation analysis of ${ }^{125}$ I-labeled Meg-CSF. Lanes $A$ through $E$ represent the decreasing concentration of the $A_{M-}$ $\operatorname{IgG}(168,42,21,10$, and $2.6 \mu \mathrm{g} / \mathrm{ml})$ used to bind the labeled protein. The iodination, immune precipitation, and subsequent analysis on $10 \%$ polyacrylamide gels were done as described in Methods. The gel was dried and exposed to X-Ray film. The position of the indicated standard proteins was determined by Coomassie Blue staining. 
Table I. Effect of the Fraction IgG Prepared from (a) Normal Rabbit Serum (NR-IgG) and (b) Serum of Immunized Rabbit $\left(A_{M}-I g G\right)$ on Colony Stimulatory Activity of Human AAS and Purified Human Meg-CSF

\begin{tabular}{|c|c|c|c|c|c|c|}
\hline \multirow[b]{2}{*}{$\begin{array}{l}\text { Treatment of hematopoietic growth } \\
\text { factor before its addition to culture }\end{array}$} & \multicolumn{6}{|c|}{ Percent colony number of control* (Dilution of IgG preparation) } \\
\hline & $\begin{array}{l}1: 4 \\
(0.672 \mathrm{mg} / \mathrm{ml})\end{array}$ & $\begin{array}{l}1: 16 \\
(0.168 \mathrm{mg} / \mathrm{ml})\end{array}$ & $\begin{array}{l}1: 64 \\
(0.042 \mathrm{mg} / \mathrm{ml})\end{array}$ & $\begin{array}{l}1: 256 \\
(0.0105 \mathrm{mg} / \mathrm{ml})\end{array}$ & $\begin{array}{l}1: 1,024 \\
(0.0026 \mathrm{mg} / \mathrm{ml})\end{array}$ & $\begin{array}{l}1: 4,096 \\
(0.00065 \mathrm{mg} / \mathrm{ml})\end{array}$ \\
\hline Human aplastic anemia serum + NR-IgG & $93 \pm 5$ & $71 \pm 13$ & $109 \pm 12$ & $92 \pm 12$ & $92 \pm 9$ & $100 \pm 9$ \\
\hline Human aplastic anemia serum $+A_{M}-$ IgG & $6 \pm 1$ & $14 \pm 1$ & $47 \pm 12$ & $55 \pm 3$ & $55 \pm 12$ & $65 \pm 7$ \\
\hline Purified human Meg-CSF + NR-IgG & $92 \pm 10$ & $71 \pm 16$ & $76 \pm 11$ & $96 \pm 19$ & $82 \pm 5$ & $88 \pm 8$ \\
\hline Purified human Meg-CSF $+A_{M}$-IgG & 0 & $12 \pm 2$ & $26 \pm 17$ & $37 \pm 8$ & $27 \pm 2$ & $92 \pm 2$ \\
\hline
\end{tabular}

* Percentage of colony numbers that developed in plates containing $0.1 \mathrm{ml}$ of the particular stimulus plus $0.1 \mathrm{ml}$ alpha-media. Data at each dilution represent the mean \pm SD of plates in two experiments. The final concentration of AAS and purified Meg-CSF in culture was $10 \%$ and $8 \times 10^{-8} \mathrm{M}$, respectively. Bone marrow mononuclear cells formed $32 \pm 4$ means \pm SD colonies when stimulated by a final $10 \%$ concentration of AAS, while $36 \pm 2$ CFU-M derived colonies per $5 \times 10^{5}$ cells plated after the addition of purified Meg-CSF. NR-IgG, preimmune rabbit IgG.

megakaryocyte colony formation. Additionally, serum, plasma and urine $(1,2)$ of thrombocytopenic patients have been shown to possess Meg-CSF activity. Meg-CSF not only increases CFU$\mathbf{M}$ cloning efficiency, but also increases the proliferative capacity of individual CFU-M as evidenced by a statistically significant increase in the numbers of cells present per colony (4). The variations in Meg-CSF levels that have been detected in different disease states suggest that alterations in the production of this regulator are physiologically important (2).

Purified regulatory molecules and cell populations must be available before we can unravel the complexities of human megakaryocytopoiesis $(29,30)$. In the study of erythropoiesis and granulopoiesis, purification of EPO, erythropoietic burst promoting activity, and various subclasses of granulocyte-macrophage colony stimulating factors have provided a better understanding of both granulopoiesis and erythropoiesis $(27,29$ 34). We have recently adopted this approach and have purified human Meg-CSF using a four-step purification scheme (7). This process has resulted in the isolation of a $46,000-\mathrm{mol}-w \mathrm{t}$ glycoprotein that promotes megakaryocyte colony formation. We have

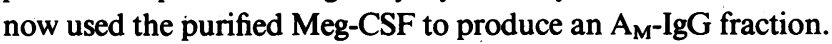
The present study shows that Meg-CSF purified from hypomegakaryocytic plasma is indeed immunogenic. Immunization of rabbits with this material has resulted in the production of an IgG fraction able to neutralize the ability of AAS as well as purified Meg-CSF to promote megakaryocyte colony formation.

Table II. Effect of Varying Concentrations of Purified Meg-CSF on the Ability of $A_{M}$-IgG to Neutralize Meg-CSF Activity

\begin{tabular}{|c|c|c|}
\hline $\begin{array}{l}\text { Treatment before addition } \\
\text { to culture }\end{array}$ & $\begin{array}{l}\text { Concentration of } \\
\text { purified Meg-CSF } \\
\text { added to culture }\end{array}$ & $\begin{array}{l}\text { Mean No. of CFU-M } \\
\text { colonies* per } 5 \times 10^{5} \\
\text { cells plated }\end{array}$ \\
\hline & $M$ & \\
\hline $\mathrm{AAS}+\mathrm{A}_{\mathbf{M}^{-}}-\mathrm{IgG}$ & 0.0 & 16.5 \\
\hline $\mathrm{AAS}+\mathrm{A}_{\mathbf{M}}-\mathrm{IgG}$ & $1 \times 10^{-8}$ & 33.0 \\
\hline $\mathrm{AAS}+\mathrm{A}_{\mathbf{M}}-\mathrm{IgG}$ & $2 \times 10^{-8}$ & 44.0 \\
\hline $\mathrm{AAS}+\mathrm{A}_{\mathbf{M}}-\mathrm{IgG}$ & $4 \times 10^{-8}$ & 55.0 \\
\hline
\end{tabular}

* To a mixture of $A_{M}-\lg$ (1:256 dilution) and 10\% AAS, increasing amounts of purified Meg-CSF were added. These mixtures were added to bone marrow cells and then plated in plasma clot cultures. Each value represents the mean of duplicate determinations.
Using standard immunological techniques we have attempted to clarify several important questions concerning the regulation of megakaryocytopoiesis. Vainchenker et al. (9) first reported that human serum contains an inhibitor of megakaryocyte colony formation. Messner et al. (26) and Kimura et al. (35) have presented evidence that plasma is superior to serum in its ability to support megakaryocyte colony formation in a methylcellulose assay system. Kimura et al. (35) also showed that the direct addition of intact or frozen-thawed platelets to methylcellulose assays resulted in a decrease in numbers of megakaryocyte colonies formed. Using a plasma clot culture system, we have not been able to detect the superiority of plateletpoor plasma-derived serum over crude serum or platelet-rich plasma-derived serum in their ability to support megakaryocyte colony formation (Hoffman, R., and E. Bruno, unpublished observations). The work demonstrating differences in the ability of plasma and serum to support colony growth have led Kimura and co-workers (35) to suggest that the enhanced ability of AAS to promote CFU-M cloning efficiency might merely be due to these sera containing less platelet-derived inhibitory activity than serum from patients with elevated platelet counts. This hypothesis would seem to be highly unlikely in light of our observation that the anti-Meg-CSF antibody can neutralize the activity of AAS to promote CFU-M cloning efficiency. In addition, the formation of a precipitin band between the anti Meg-CSF IgG fraction and AAS and normal serum also suggests the presence of an immunologically distinct macromolecule in these specimens which share a common polypeptide segment.

Since a number of investigators have reported that EPO and TSF can support megakaryocyte colony formation $(18,27,28)$, it was important to determine the relationship between TSF, EPO, and purified Meg-CSF. We have previously reported that neither TSF nor EPO increases megakaryocyte colony formation (4). The inability of the anti-Meg-CSF antibody to react with either TSF or EPO suggests that these factors are at least immunologically unrelated molecules. The possibility does exist that at high concentrations of TSF or EPO that are artificially created in clonal assay systems, either of these factors might influence in vitro megakaryocyte colony formation. It would appear unlikely, however, that either TSF or EPO are primary physiological regulators of megakaryocytopoiesis at the level of the CFU-M.

Interleukin 3 (IL-3) is a lymphokine first defined by its capacity to induce 20 - $\alpha$-hydroxysteroid dehydrogenase (20- $\alpha$-SDH) 
Table III. Neutralization of CFU-M, CFU-E, BFU-E, CFU-GM, and CFU-GEMM

Stimulatory Activity by Normal Rabbit and Anti-Meg-CSF IgG

\begin{tabular}{|c|c|c|c|c|c|}
\hline $\begin{array}{l}\text { Prior treatment of hematopoietic growth factor } \\
\text { to its addition to culture }\end{array}$ & $\begin{array}{l}\text { CFU-M derived colonies* } \\
\text { per } 5 \times 10^{5} \text { cells plated }\end{array}$ & $\begin{array}{l}\text { CFU-E derived colonies* } \\
\text { per } 5 \times 10^{5} \text { cells plated }\end{array}$ & $\begin{array}{l}\text { BFU-E derived colonies* } \\
\text { per } 5 \times 10^{3} \text { cells plated }\end{array}$ & $\begin{array}{l}\text { CFU-GM derived } \\
\text { colonies* per } 1 \times 10^{5} \\
\text { cells plated }\end{array}$ & $\begin{array}{l}\text { CFU-GEMM } \\
\text { per } 1 \times 10^{5} \\
\text { cells plated }\end{array}$ \\
\hline None & $3 \pm 1$ & $0 \pm 0$ & $0 \pm 0$ & $6 \pm 4$ & $0 \pm 0$ \\
\hline Human EPO $(1 \mathrm{U} / \mathrm{ml})$ & $4 \pm 2$ & $270 \pm 46$ & $119 \pm 13$ & $37 \pm 10$ & $4 \pm 2$ \\
\hline Human EPO $(1 \mathrm{U} / \mathrm{ml})+$ NR-IgG & NA & $288 \pm 17, \mathrm{NS}$ & $129 \pm 4, \mathrm{NS}$ & NA & NA \\
\hline Human EPO $(1 \mathrm{U} / \mathrm{ml})+\mathrm{A}_{\mathbf{M}}-\mathrm{IgG}$ & NA & $294 \pm 22, \mathrm{NS}$ & $139 \pm 29, \mathrm{NS}$ & NA & NA \\
\hline AAS & $36 \pm 2$ & NA & NA & NA & NA \\
\hline AAS + NR-IgG & $33 \pm 5, \mathrm{NS}$ & NA & NA & NA & NA \\
\hline $\mathrm{AAS}+\mathrm{A}_{\mathbf{M}}-\mathrm{IgG}$ & $5 \pm 0 \mathrm{P}=0.000025$ & NA & NA & NA & NA \\
\hline PHA-LCM & $1 \pm 0$ & NA & NA & $100 \pm 24$ & NA \\
\hline PHA-LCM + NR-IgG & NA & NA & NA & $103 \pm 10, \mathrm{NS}$ & NA \\
\hline PHA-LCM + A $_{M}-$ IgG & NA & NA & NA & $113 \pm 15, \mathrm{NS}$ & NA \\
\hline PHA-LCM + human EPO & NA & NA & $66 \pm 9$ & NA & $13 \pm 4$ \\
\hline PHA-LCM + human EPO + NR-IgG & NA & NA & $76 \pm 10$ & NA & $12 \pm 1, \mathrm{NS}$ \\
\hline PHA-LCM + human EPO + A $_{M}-\mathrm{IgG}$ & NA & NA & $87 \pm 4$ & NA & $20 \pm 5, \mathrm{NS}$ \\
\hline
\end{tabular}

* Bone marrow cells were incubated with a 1:16 dilution of the $\mathrm{A}_{\mathrm{M}}$-IgG or NR-IgG and either erythropoietin, AAS (10\%), or PHA-LCM (5\%) and then plated in plasma clot or methylcellulose cultures. Each value represents the mean \pm SD of either duplicate or quadruplicate cultures. NA, not available. NR-IgG, preimmune rabbit IgG. $A_{M}-I g G$, anti-Meg-CSF IgG. NS, not significant.

in spleen cells of neonatal nude mice (37). IL-3 has been purified to homogeneity and its responsible gene cloned $(37,38)$. IL-3 has been shown to possess a number of hematopoietic growth factor-like activities (39). Quesenberry and co-workers (40) have presented data that suggest that IL-3 is a potent stimulator of in vitro murine megakaryocyte colony formation. IL-3 appears to represent the marrow cell-line inducing activity present in media conditioned by the murine myelomonocyte cell line WEHI-3 (41). WEHI-3 cell conditioned medium has also been used as a source of murine Meg-CSF. Recently, Williams and co-workers (42) have shown that the Meg-CSF in WEHI-3 cell conditioned medium was identical to IL-3. The relationship of human Meg-CSF to IL-3 is unknown. Unfortunately, there is no purified human molecule equivalent to murine IL-3 available with which to define this relationship. However, this issue was explored using the anti-Meg-CSF IgG fraction. Crude PHA-LCM prepared from human mononuclear cells possesses many IL-3like activities (43). The PHA-LCM had burst promoting activity, granulocyte-macrophage colony stimulating activity, and multipotential colony stimulating activity. The $A_{M}$-IgG fraction was able to neutralize the ability of AAS and purified Meg-CSF to stimulate megakaryocyte colony formation but did not alter the ability of PHA-LCM to support CFU-GM, CFU-GEMM, or BFU-E derived colony formation. In addition, using Western blotting, we were unable to detect any Meg-CSF in several different batches of PHA-LCM (data not shown). These data suggest that the purified Meg-CSF is immunologically distinct from the IL-3-like activity present in PHA-LCM.

The detection of Meg-CSF in normal serum using $A_{M^{-}}-I g G$ as an immunological probe was a surprising finding. This data would suggest that detectable levels of this factor are present in most individuals in order to maintain baseline megakaryocytopoiesis and thrombopoiesis. These findings are consistent with previous data published by our laboratory, which suggest that Meg-CSF is required in vitro at higher concentrations than previously recognized for other hematological growth factors ( 7 ,
43, 44). The reasons for this discrepancy are unknown to us, but could indicate the unique properties of Meg-CSF.

The data presented in this report clearly demonstrate the presence of Meg-CSF in AAS and normal serum. This factor appears to play a pivotal role in the regulation of megakaryocytopoiesis. Although we have been unable to detect a serum inhibitor of megakaryocyte colony formation, our results do not exclude the presence of such a factor. The possibility arises that the methylcellulose assay system might be more sensitive in the detection of such inhibitors than the plasma clot culture system. Our present studies, however, do clearly define the presence of Meg-CSF-like activity in human serum. Whether the effect of this factor can be blunted by inhibitory molecules originating in platelets is a question that we are now approaching, using a better defined serum-free culture system.

\section{Acknowledgments}

We thank Dr. T. P. McDonald for supplying the purified thrombopoietic stimulatory factor and Dr. G. Beyer for providing the PHA-LCM. Additional thanks are extended to Linda Cheung, Shirley Duke, and Stephanie Moore for their secretarial support.

This work was supported by grant No. 2R01CA34841-03A1 from the National Institutes of Health. Dr. Hoffman received a Research Cancer Development Award.

\section{References}

1. Enomoto, K., M. Kawakita, S. Kishimoto, N. Katayama, and T. Miyake. 1980. Thrombopoiesis and megakaryocyte colony stimulating factor in the urine of patients with aplastic anemia. Br. J. Haematol. 45: $551-556$.

2. Hoffman, R., E. Mazur, E. Bruno, and V. Floyd. 1981. Assay of an activity in the serum of patients with disorders of thrombopoiesis that stimulates formation of megakaryocyte colonies. $N$. Engl. J. Med. 305:533-538. 
3. Kawakita, M., M. Ogawa, E. Goldwasser, and T. Miyake. 1983. Characterization of human megakaryocyte colony-stimulating factor in the urinary extracts from patients with aplastic anemia and idiopathic thrombocytopenic purpura. Blood. 61:556-560.

4. Mazur, E. M., R. Hoffman, and E. Bruno. 1981. Regulation of human megakaryocytopoiesis. An in vitro analysis. J. Clin. Invest. 68 : 733-741.

5. Williams, N., R. R. Eger, H. M. Jackson, and D. J. Nelson. 1982. Two factor requirement for murine megakaryocyte colony formation. J. Cell. Physiol. 110:101-104.

6. McDonald, T. P. 1981. Assay and site of production of thrombopoietin. Br. J. Haematol. 49:493-499.

7. Hoffman, R., H. H. Yang, E. Bruno, and J. Straneva. 1985. Purification and partial characterization of a megakaryocyte colony stimulating factor from human plasma. J. Clin. Invest. 75:1174-1182.

8. Mazur, E. M., R. Hoffman, J. Chasis, S. Marchesi, and E. Bruno. 1981. Immunofluorescent identification of human megakaryocyte colonies using an antiplatelet glycoprotein antiserum. Blood. 57:277-286.

9. Vainchenker, W., J. Chapman, J. F. Deschamps, G. Vinci, J. Bouguet, M. Titeux, and J. Breton-Gorius. 1982. Normal human serum contains a factor(s) capable of inhibiting megakaryocyte colony formation. Exp. Hematol. 10:650-660.

10. Lowry, O. H., N. J. Rosebrough, A. L. Farr, and R. J. Randall. 1951. Protein measurements with the Folin phenol reagent. J. Biol. Chem. 193:265-272.

11. Laemmli, V. K. 1980. Cleavage of structure proteins during the assembly of the head of bacteriophage $\mathrm{T}_{4}$. Nature (Lond.). 227:680-685.

12. O'Farrell, P. H., and H. Palrids. 1975. High resolution two-dimensional electrophoresis of proteins. J. Biol. Chem. 250:4007-4021.

13. Grabar, P., and C. A. Williams. 1953. Méthode permettant létude conjuguée des propriétés électrophorétiques et immunochimiques d' un mélange de protéines. Application au serum sanguin. Biochim. Biophys. Acta. 10:193-194.

14. Ouchterlony, O., and L. A. Nilsson. 1973. Immunodiffusion and immunoelectrophoresis. In Handbook of Experimental Immunology, Vol. 1. D. M. Weir, editor. Blackwell Scientific Publications, Oxford.

15. Stanley, E. R., and L. J. Guilbert. 1981. Methods for the purification assay, characterization and target cell binding of a colony stimulating factor (CSF-1). J. Immunol. Methods. 42:253.

16. Stagg, B. H., J. N. Temperley and H. Rochman. 1970. Iodination and the biological activity of gastrin. Nature (Lond.). 228:58-59.

17. Towbin, H., T. Stachelin, and J. Gordon. 1979. Electrophoretic transfer of proteins from polyacrylamide gels to nitrocellulose sheets: procedure and some applications. Proc. Natl. Acad. Sci. USA. 76:43504354.

18. McLeod, D. L., M. M. Shreeve, and A. A. Axelrad. 1976. Induction of megakaryocyte colonies with platelet formation in vitro. Nature (Lond.). 261:492-494.

19. Ritchey, A. K., R. Hoffman, E. Coupal, V. Floyd, H. A. Pearson, and B. G. Forget. 1981. Imbalanced globin chain synthesis in cultured erythroid progenitor cells from thalassenic bone marrow and peripheral blood. Blood. 57:788-793.

20. Fauser, A. A., and H. A. Messner. 1978. Granuloerythropoietic colonies in human bone marrow, peripheral blood and cord blood. Blood. 52:1243-1248.

21. Fauser, A. A., and H. A. Messner. 1979. Identification of megakaryocytes, macrophages and eosinophils in colonies of human bone marrow containing neutrophilic granulocytes and erythroblasts. Blood. 53:1023.

22. Nakeff, A., and S. Daniels-McQueen. 1976. In vitro colony assay for a new class of megakaryocyte precursor: colony-forming unit megakaryocyte (CFU-M). Proc. Soc. Exp. Biol. Med. 151:587-590.

23. Metcalf, D., H. R. McDonald, N. Odartchenko, and B. Sordat. 1975. Growth of mouse megakaryocyte colonies in vitro. Proc. Natl. Acad. Sci. USA. 72:1744-1748.
24. Penington, D. G. 1979. Megakaryocyte colony culture using a liver cell conditioned medium. Blood Cells. 5:13-23.

25. Williams, N., H. Jackson, A. P. C. Sheridan, M. J. Murphy, Jr., A. Elste, and M. A. S. Moore. 1982. Regulation of megakaryopoiesis in long-term murine bone marrow cultures. Blood. 51:245-255.

26. Messner, H. A., N. Jamal, and C. Izaguirre. 1982. The growth of large megakaryocyte colonies from human bone marrow. J. Cell. Physiol. Suppl. 1:45-51.

27. Vainchenker, N., and J. Breton-Gorius. 1979. Megakaryocyte colony formation by human blood and marrow precursors. Blood. 54: 940-945.

28. Freedman, M. H., and E. F. Saunders. 1981. Differentiation of murine megakaryocyte progenitors (CFU-M): Humoral control in vitro. Cell Tissue Kinet. 14:53-58.

29. Metcalf, D., and N. A. Nicola. 1983. Proliferative effects of purified granulocyte colony-stimulating factor (G-CSF) on normal mouse hemopoietic cells. J. Cell. Physiol. 116:198-206.

30. Miyake, T., C. K. H. Kung, and E. Goldwasser. 1977. Purification of human erythropoietin. J. Biol. Chem. 252:5558-5564.

31. Burgess, A. W., J. Camakaris, and D. Metcalf. 1977. Purification and properties of colony stimulating factor from mouse lung-conditioned medium. J. Biol. Chem. 252:1998-2203.

32. Porter, P. N., and M. Ogawa. 1982. Characterization of human erythroid burst-promoting activity derived from bone marrow conditioned media. Blood. 59:1207-1212.

33. Stanley, E. R., and P. M. Heard. 1977. Factors regulating macrophage production and growth: Purification and some properties of the colony stimulating factor from medium conditioned by mouse $\mathrm{L}$ cells. J. Biol. Chem. 252:4305-4312.

34. Waheed, A., and R. K. Shadduck. 1982. Purification of colony stimulating factor by affinity chromatography. Blood. 60:238-244.

35. Kimura, H., S. A. Burstan, D. Thorning, J. S. Powell, L. A. Harker, P. J. Fialkow, and J. W. Adamson. 1984. Human megakaryocyte progenitors (CFU-M) assayed in methylcellulose: physical characteristics and requirements for growth. J. Cell. Physiol. 118:87-96.

36. Ihle, J. N., L. Pepersack, and L. Rebar. 1981. Regulation of T cell differentiation: In vitro induction of $20-\alpha$-hydroxysteroid dehydrogenase in splenic lymphocytes from athymic mice by a unique lymphokine. J. Immunol. 126:2184-2189.

37. Ihle, J. N., J. Keller, S. Oraszlan, L. E. Henderson, T. D. Copeland, F. Fitch, M. B. Prystowsky, E. Goldwasser, J. Schrader, E. Palaszynski, M. Dy, and B. Lebel. 1983. Biologic properties of hemogeneous interleukin 3. J. Immunol. 131:282-287.

38. Rennick, D. M., F. D. Lee, T. Yokota, K.-I. Arai, H. Cantor, and G. J. Nabel. 1985. A cloned mast cell growth factor cDNA encodes a multilineage hematopoietic growth factor: Multiple activities of interleukin 3. J. Immunol. 134:910-914.

39. Goldwasser, E., J. N. Ihle, M. B. Prystowski, J. Rick, and G. Van Zant. 1983. The effect of interleukin-3 on hemopoietic precursor cells. In Normal and Neoplastic Hematopoiesis. Alan R. Liss, Inc. New York. 301-309.

40. Quesenberry, P. J., J. N. Ihle, and E. McGrath. 1985. The effect of interleukin 3 and GM-CSA-2 on megakaryocyte and myeloid clonal colony formation. Blood. 65:214-217.

41. Dexter, T. M., J. Garland, D. Scott, E. Scolnick, and D. Metcalf. 1980. Growth of factor dependent hemopoietic precursor cell lines. $J$. Exp. Med. 152:1036-1047.

42. Williams, N., R. Sparrow, K. Gill, D. Yasmeen, and I. McNiece. 1985. Murine megakaryocyte colony stimulating factor: its relationship to interleukin-3. Leuk. Res. 9:1487-1496.

43. Cutler, L., D. Metcalf, N. A. Nicola, and G. R. Johnson. 1985. Purification of a multipotential colony-stimulating factor from pokeweed mitogen-stimulated mouse spleen cell conditioned medium. J. Biol. Chem. 260:6579-6587.

44. Metcalf, D. 1985. The granulocyte macrophage colony-stimulating factors. Science (Wash. DC). 229:16-22. 